\title{
Studies on the interaction between Odoiporous longicollis and endophytic Beauveria bassiana by establishing fungal infection to bsw in the plant system
}

\author{
M.K. PRABHAVATHI* AND S.K. GHOSH
}

Department of Entomology, University of Agricultural Sciences, GKVK, BANGALORE (KARNATAKA) INDIA

\section{ARITCLE INFO}

$\begin{array}{ll}\text { Received } & : 24.03 .2014 \\ \text { Revised } & : 23.07 .2014 \\ \text { Accepted } & : 07.08 .2014\end{array}$

\section{KEY WORDS :}

Beauveria bassiana Balsamo, Odoiporous longicollis

*Corresponding author:

Email:prabhavathient@gmail.com

\begin{abstract}
Beauveria bassiana, which is effective entomopathogen against a variety of insect pests, is the most researched and commercialised fungal biopesticide. Laboratory and screenhouse studies have revealed great potential of this entomopathogenic fungus for use against the banana weevil, Odoiporous longicollis, in banana. Result revealed that B. bassiana can colonise internal banana tissues for at least four months after tissue-cultured plantlets are dipped in a spore suspension. The type of banana cultivar did not affect colonisation by Beauveria bassiana and, even when elevated $B$. bassiana doses were used, plant growth was not reduced. In a set of three screen house experiments, weevil mycosis rates in B. bassiana-treated plants were 50-70 per cent within 10 - 15 days when the adult weevils were allowed to infest the banana plantlets having B.bassiana as a endophyte in their systems prior to infest. And the presence of the fungus inside treated plants led to a reduction in pseudostem weevil damage up to $>50$ per cent. Application of $B$. bassiana as an artificial endophyte inside banana plants could circumvent bottlenecks associated with its application as a conventional biopesticide, because (i) it kills the damaging larval stages inside the plant, (ii) it is protected from adverse biotic and abiotic factors, (iii) little inoculum is required, drastically reducing its cost, and (iv) farmers do not need to apply the biological control organism themselves, as the technology is easily transferable to a commercial tissue culture producer.
\end{abstract}

How to view point the article : Prabhavathi, M.K. and Ghosh, S.K. (2014). Studies on the interaction between Odoiporous longicollis and endophytic Beauveria bassiana by establishing fungal infection to BSW in the plant system. Internat. J. Plant Protec., 7(2) : 312-317. 